\title{
Recovery of Fast Neutron Irradiated Molybdenum
}

\author{
By R. Hanada*, S. Takamura**, S. Okuda** \\ and H. Kimura*
}

\begin{abstract}
Recovery spectra of Mo fast neutron irradiated at $10^{\circ} \mathrm{K}$ was determined by an electrical resistivity measurement from stage I to stage III.

The effect of radiation doping at room temperature upon the stages I and II recovery was also investigated and it was found that the stages I and II recovery is enhanced by the doping.

The stage III recovery was studied in only doped and in doped and subsequently low temperature irradiated specimens.

The enhancement phenomenon was discussed in conjunction with the stage III recovery study.

(Received August 13, 1970)
\end{abstract}

\section{Introduction}

Compared with $f c c$ metals, the radiation damage studies in $b c c$ metals are quite few. The present work is aimed to study recovery processes in $b c c$ metals from stage I to stage III after fast neutron irradiation near liquid helium temperature.

Molybdenum is chosen as a $b c c$ metal specimen for reasons that it has no phase transition between $4.2^{\circ} \mathrm{K}$ and its melting point, and also it is not superconductive at liquid helium temperature where the residual resistivity measurement is performed. Furthermore, radiation damage studies in Mo so far reported are mostly limited to the recovery studies above room temperature ${ }^{(1) \sim(3)}$. The recovery studies in a low temperature range were fragmentary and performed on the specimens with a high concentration of impurities with an exception of that by Coltman et al. (4), where they used Mo specimens with the resistivity ratio of 1500 . However, Coltman et al. used thermal neutrons as irradiating particles, and hence no fast neutron damage work on Mo is available at present except the preliminary work $^{(5)}$, where specimens with resistivity ratio of $5 \sim 10$ were used. Luccason and Walker ${ }^{(6)}$ investigated the recovery of electron irradiated Mo from $4.3^{\circ} \mathrm{K}$ to $70^{\circ} \mathrm{K}$ and resolved recovery stages at $28^{\circ}, 35^{\circ}$ and $42^{\circ} \mathrm{K}$. Coltman et al. ${ }^{(4)}$ also found similar stages in their thermal neutron damaged specimens. Recently, Lomer et al. (7) investigated the recovery process in electron irradiated Mo by means of internal friction and suggested that a long range migration of interstitials is taking place between $50^{\circ}$ and $70^{\circ} \mathrm{K}$.

Several experiments have been performed on the stage III recovery in Mo af ter neutron ${ }^{(1)(3)}$ and electron irradiation $^{(2)}$. However, there still exists a contradiction on the species of the defect which is mobile and annihilate in stage III. One school of thought attributes to the

* The Research Institute for Iron, Steel and Other Metals, Tohoku University, Sendai, Japan.

* Japan Atomic Energy Research Institute, Tokai, Ibaraki, Japan.

(1) G.H.Kinchin and M.W.Thompson : J. Nucl. Energy, 6 (1958), 275.

(2) M. DeJong and H. B. Afman : Acta Met., 15 (1967), 1.

(3) J. Nihoul : Radiation Damage in Solids, I. A. E. A.,(1962), p. 309 .

Trans. J I M stage III vacancy migration and the other to interstitials migration.

The electron microscopic study on neutron irradiated Mo by Downey and Eyre ${ }^{(8)}$ showed that interstitial clusters are present after room temperature irradiation, which suggests that one kind of interstitials are mobile at room temperature. The measurement of the damage rate at liquid nitrogen temperature in nitrogen doped Mo also suggests that a long range migration of interstitials is taking place at this temperature ${ }^{(9)}$. Hence, if one assigns the migration of interstitials to stage III, the interstitial should be of different type from the one mobile below room temperature.

A defect doping experiment has been performed on $\mathrm{Pt}$ by Swanson ${ }^{(10)}$, where dopants were dislocations, impurities and quenched-in vacancies. He found that the damage rate was increased by the presence of vacancies. Herschbach and Jackson ${ }^{(1)}$ also doped Pt by quenchedin vacancies and found that the stage $I$ recovery was enhanced by the doping. They interpreted the enhancement of the recovery in terms of the additional sinks due to the doping.

The present research has two aims. The first is to determine the general recovery structures in fast neutron irradiated Mo of various purities from stage I to stage III. The second is to see the effect of defect doping at room temperature on the annealing behavior of defects introduced by low temperature irradiation. The second aim is to investigate the interaction between the defects produced by doping and low temperature irradiation. This may give us some clue to determine the species of defects responsible for stage III and above. Different from $f c c$ metals, room temperature, where the doping irradiation is given, is far below the stage III temperature

(4) R. R. Coltman, C. E. Klabunde and J.K. Redman : Phys. Rev., 156 (1967), 715.

(5) S. Takamura, H. Maeta and S. Okuda : J. Phys. Soc. Japan, 25 (1968), 418.

(6) P.G. Lucasson and R. M. Walker : Phys. Rev., 127 (1962), 485.

(7) N. J. Lomer and R. J. Taylor : Phil. Mag., 19 (1969), 437.

(8) M. E. Downey and B. L. Eyre : Phil. Mag., 11 (1965), 53.

(9) J.G. Evans : Private communication.

(10) M. L. Swanson : phys. stat. sol., 23 (1967), 644.

(11) J. J. Jackson and K. Herschbach : Phys. Rev., 173 (1968), 664.

1970 Vol.11 
and hence defects responsible for stage III and above are present as isolated defects after the doping treatment.

\section{Experimental Procedure}

The method of the resistivity measurement is described elsewhere ${ }^{(12)}$. Isochronal annealing was performed after fast neutron irradiation at about $10^{\circ} \mathrm{K}$. The holding time was 6 minutes throughout stages I and II. The temperature interval was selected as $2^{\circ} \mathrm{K}$ below $70^{\circ} \mathrm{K}$, and between $70^{\circ} \mathrm{K}$ and room temperature, a logarithmic annealing schedule was employed, where the $i$-th annealing point was chosen so as to make $\log T_{i}-\log T_{i-1}$ to be constant. The isochronal annealing above room temperature was performed in a silicon oil bath whose temperature was controlled within $\pm 0.5^{\circ} \mathrm{C}$. The holding time was $40 \mathrm{~min}$ and the temperature interval was $10^{\circ} \mathrm{C}$. In all experiments, specimens with different treatments were simultaneously annealed, so that they were given the same history of heat treatment.

\section{Specimen preparation}

Molybdenum wire of $50 \mu \mathrm{m}$ diameter was purchased from Materials Research Corp. and the resistivity ratio between room temperature and the liquid He temperature was 5 to 10 in the as-received state. The specimen was first annealed at $2100^{\circ} \mathrm{K}$ in wet and dry hydrogen for $5 \mathrm{hr}$. Next, the specimen was annealed under ultra high vacuum $\left(10^{-9}\right.$ Torr.) for $5 \sim 6$ days at $2000^{\circ} \mathrm{K}$. After these treatments, the final resistivity ratio was increased to $4.00 \sim 1000$ without any size correction*.

The specimen was mounted on a mica strip protected by a silica tube. Both ends of the specimen were soldered with the solder for Mo as described by DeJong and Afman ${ }^{(2)}$ on heads of $1 \mathrm{~mm}$ screws. An experiment on a specimen without irradiation showed that no impurity pick-up from the solder as well as silicon oil bath took place up to $240^{\circ} \mathrm{C}$.

\section{Results}

\section{Damage rate}

Table 1 shows the results of damage rate measurements in Mo irradiated in the JRR-3 reactor near liquid helium temperature. In the present experimental procedure, the damage rate could be determined only by measuring final resistivity increase at the end of the irradiation. The accuracy of the procedure is considered to be lower than the usual procedure of damage rate measurements based on the slope of the resistivity vs. dose curve.

Damage rate measurements in 12-, 22- and 64-hr doped

Table 1 Damage rate of Mo at liquid helium temperature. The doping treatment does not give much difference in the damage rate when the average is taken

\begin{tabular}{|c|c|c|}
\hline $\begin{array}{c}\text { Damage rate } \\
\left(\times 10^{-9} \Omega-\mathrm{cm} / \mathrm{hr}\right)\end{array}$ & Average & Treatments \\
\hline $\begin{array}{l}1.165 \\
1.164 \\
1.182 \\
1.120 \\
1.131 \\
1.125 \\
1.295\end{array}$ & $1.158 \pm 0.02$ & $\begin{array}{l}\text { As-anneal } \\
\text { As-anneal } \\
\text { As-anneal } \\
\text { As-anneal } \\
12 \mathrm{hrs} \text { dope } \\
22 \mathrm{hrs} \text { dope } \\
64 \mathrm{hrs} \text { dope }\end{array}$ \\
\hline
\end{tabular}

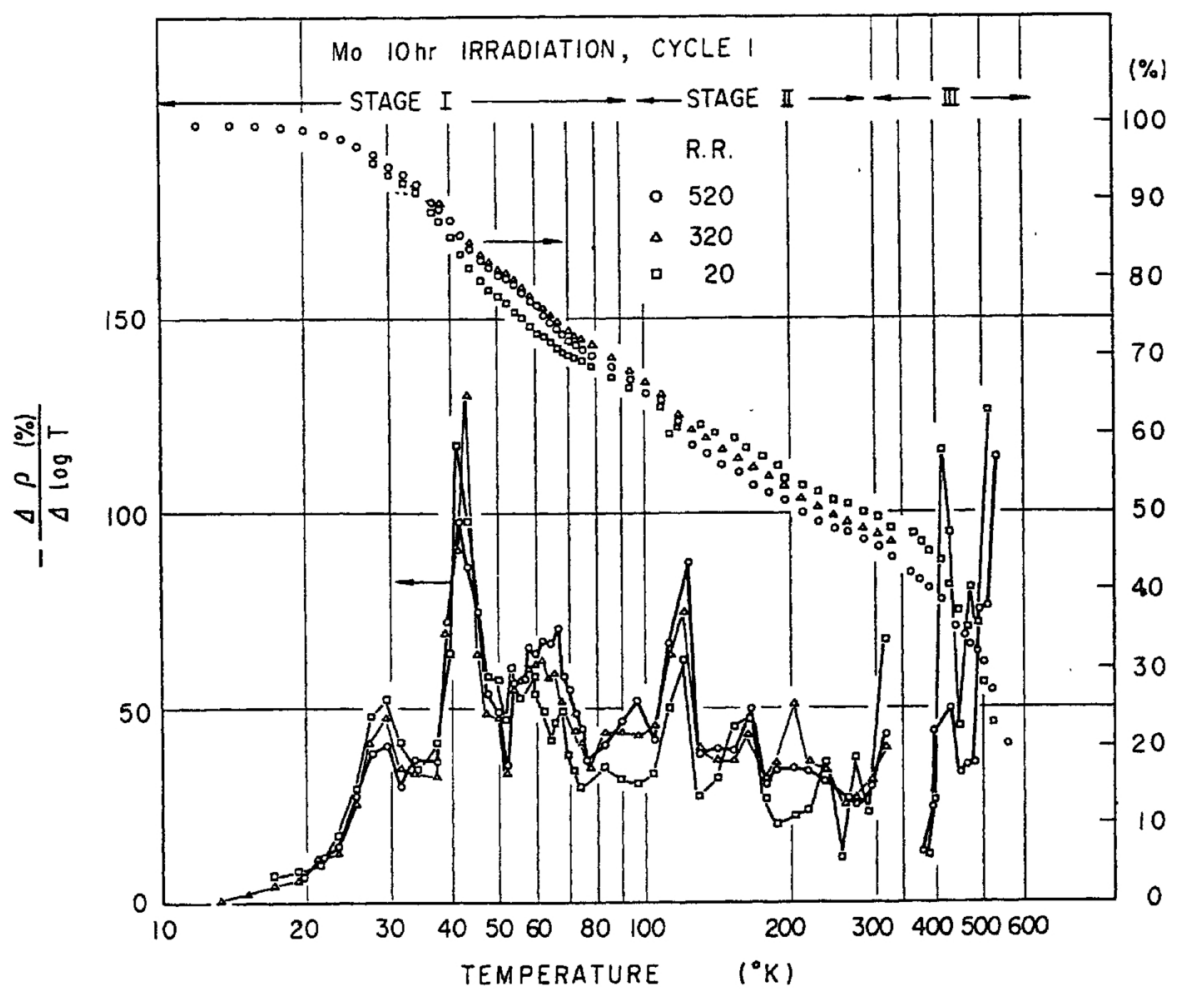

Fig. 1 Recovery structures in the $10 \mathrm{hr}$ fast neutron irradiated Mo specimens. Three curves correspond to three different purity specimens (Resistivity ratio $520,320,20$ ). Note that the $60^{\circ} \mathrm{K}$ substage shows systematic retardation with increasing impurity contents.

(12) S. Takamura, H. Maeta and S. Okuda : J. Phys. Soc. Japan, $26(1969), 1120$.
* We are grateful to Mr. M. Suezawa (Res. Inst. Iron, Steel and Other Metals) for his advice and assistance in the preparation of the specimens. 
specimens show, within the present experimental accuracy, no systematic enhancement in damage rate, as observed in $\mathrm{Pt}^{(11)}$.

\section{Recovery in as-annealed specimens}

Fig. $I$ shows the recovery structure in stage $\mathrm{I}\left(4.2^{\circ} \sim\right.$ $\left.100^{\circ} \mathrm{K}\right)$, stage II $\left(100^{\circ} \sim 300^{\circ} \mathrm{K}\right)$ and stage III $\left(300^{\circ} \sim\right.$ $600^{\circ} \mathrm{K}$ ) in a $10 \mathrm{hr}$ irradiated specimens. The three recovery curves-correspond to those of three different purity specimens. As shown in Fig. 1, the recovery structure is not strongly dependent on the purity of the specimen except for the substage between $50^{\circ}$ and $70^{\circ} \mathrm{K}$. In this substage, a systematic decrease of the amount of recovery with the impurity content is observed.

Most of the peaks in stage II are not reproducible except the one at $120^{\circ} \mathrm{K}$, which is also observed by Coltman et al. ${ }^{(4)}$

\section{Recovery in doped specimens}

Fig. 2 shows the typical recovery structures in three Mo specimens with different treatments before low temperature irradiation. These treatments are (1) asannealed, (2) doped for $64 \mathrm{hr}$ and (3) doped for $64 \mathrm{hr}$ and annealed at $400^{\circ} \mathrm{C}$ for $1 \mathrm{hr}$.

As seen from Fig. 2, the doped specimen shows a remarkable increase in recovery amount in stages I and II, whereas the specimen doped and subsequently annealed at $400^{\circ} \mathrm{C}$ almost loses the effect of the doping. Although not shown in the figure, a specimen doped and subsequently annealed at $200^{\circ} \mathrm{C}$ loses about half the effect of the doping. No change in the temperature positions of peaks was detected in the doped specimen compared with the annealed specimen.

By changing the doping time by 12,22 and $64 \mathrm{hr}$, it was found that the enhancement tends to saturate with increasing doping dose (see Table 2). This will be discussed later in conjunction with the damage rate at room temperature, which also shows the saturation tendency.

Table 2 Summary of the stages I and II enhancement due to the doping. The amount of the enhancement at the end of stage II $\left(308^{\circ} \mathrm{K}\right)\left(\Delta \rho_{E}\right)$ is given in terms of $(\%)$ and $(\Omega-\mathrm{cm}) . \Delta \rho_{D}$ gives the resistivity increase during doping irradiation. The ratio $\Delta \rho_{E} / \Delta \rho_{D}$ is almost constant regardless the amount of the doping dose. This fact indicates that the enhancement is proportional to the concentration of defects introduced by the doping

\begin{tabular}{r|r|c|c|c|c}
\hline $\begin{array}{c}\text { Dope } \\
(\mathrm{hr})\end{array}$ & $\Delta \rho_{D}^{*}$ & $\begin{array}{c}\text { Recovery } \\
\left(\%^{2} \text { at } 308^{\circ} \mathrm{K}\right)\end{array}$ & $\begin{array}{c}\Delta \rho_{E} \\
(\%)\end{array}$ & $\begin{array}{c}\Delta \rho_{L}^{*} \\
\left(\Omega_{-\mathrm{cm})}\right)\end{array}$ & $\Delta \rho_{E} / \Delta \rho_{D}$ \\
\hline 0 & - & 48 & 0 & 0 & - \\
12 & 4.3 & 54 & 6 & $0.7^{* *}$ & 0.17 \\
22 & 7.5 & 60 & 12 & $1.4^{* *}$ & 0.18 \\
64 & 12.0 & 67 & 19 & $2.2^{* * *}$ & 0.18 \\
\hline
\end{tabular}

$*$ In unit of $10^{-9} \Omega-\mathrm{cm}$

** Normalized to $10 \mathrm{hr}$ low temp. Irrad.

One should also note that the enhancement is not due to the enhanced production of stages I and II defects in the doped specimens. If this were the case, the damage rate would be enhanced by the doping treatment. No such enhancement of the damage rate was observed in the present experiment.

As shown in Fig. 3, where the ratios of the differential recovery curves in the doped to the as-annealed specimens are plotted, the enhancement starts at about $28^{\circ} \mathrm{K}$ and continues to proceed up to room temperature.

\section{Stage III recovery in doped specimens}

Fig. 4 shows the differential recovery curves of stage

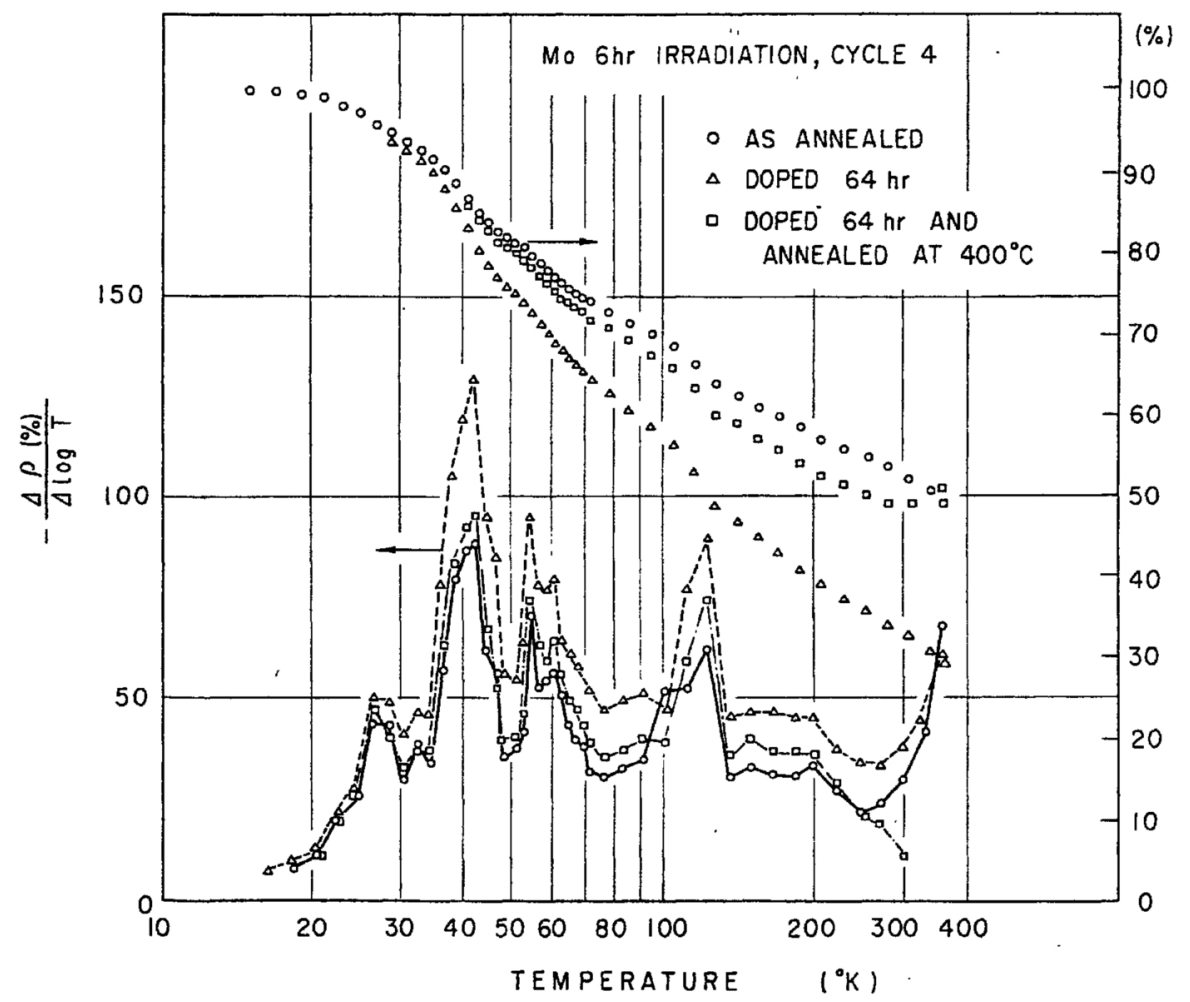

Fig. 2 Recovery structures in the radiation doped Mo specimens. $(\Delta)$ shows the recovery of the $64 \mathrm{hr}$ doped specimen, whereas ( $\square$ ) shows the recovery of the doped and subsequently annealed at $400^{\circ} \mathrm{C}$ specimen. The recovery of the as-annealed specimen (O) is also shown for comparison. 


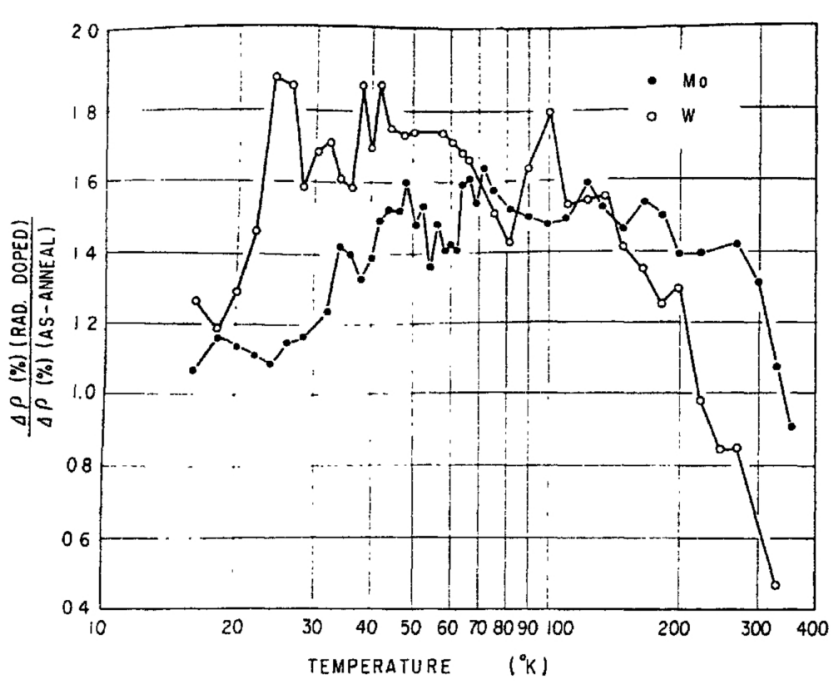

Fig. $3\left(\Delta \rho(\%) / \Delta T_{i}\right)$ Doped $/\left(\Delta \rho(\%) / \Delta T_{i}\right)_{\text {As_anneal }}$ is plotted against the annealing temperature to show the enhancement more clearly. The same curve for $W$ is also shown. and $\Delta \rho_{D}(\mathrm{IV}, \mathrm{V})$ is the resistivity to recover above stage III. In the second specimen (specimen 2), to which the doping and low temperature irradiation are given, the resistivity remaining is given by

$$
\begin{gathered}
\Delta \rho_{2}=\Delta \rho_{D}^{\prime}(\mathrm{III})+\Delta \rho_{L . I .}^{\prime}(\mathrm{III})+\Delta \rho_{D}^{\prime}(\mathrm{IV}, \mathrm{V}) \\
+\Delta \rho_{L .1 .}^{\prime}(\mathrm{IV}, \mathrm{V}),
\end{gathered}
$$

where $\Delta \rho_{L . I}^{\prime}$. (III) is the resistivity due to low temperature irradiation to recover in stage III.

The resistivity remaining in the specimen (specimen 3 ), which is only irradiated at low temperature, is given by

$$
\Delta \rho_{3}=\Delta \rho_{L . I .}(\mathrm{III})+\Delta \rho_{L . I .}(\mathrm{IV}, \mathrm{V}) .
$$

If it is assumed that the stage III defect is not lost during the processes of stages I and II enhanced by the doping, there should be a relation

$$
\Delta \rho_{D}^{\prime}(\mathrm{III})+\Delta \rho_{L . I .}^{\prime}(\mathrm{III})=\Delta \rho_{D}(\mathrm{III})+\Delta \rho_{L . I .}(\mathrm{III})
$$

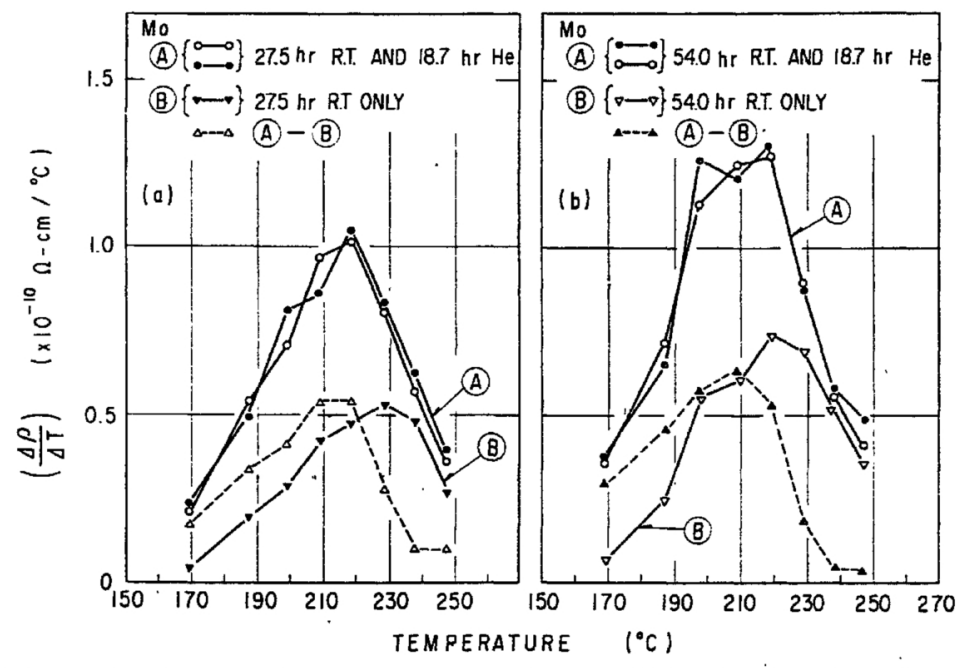

Fig. 4 The differential recovery curves of the stage $\mathrm{III}$ in the olny doped (B) and the doped and low temperature irradiated (A) specimens. Fig. 4(a) shows the results of the $27.5 \mathrm{hr}$ doping time, Fig. 4 (b) is for the $54.0 \mathrm{hr}$ doping time. Low temperature irradiation time was $18.7 \mathrm{hr}$ in both case. The dashed lines show the difference, A-B, in order to compare the results with the only low temperature irradiated specimen (see Fig. 5).

III in two specimens with different treatments, namely, one doped at room temperature without any further irradiation and the other doped at room temperature and further irradiated at liquid helium temperature. The actual procedure was as follows; two specimens were given radiation doping at the same time at room temperature for a given time. After the induced resistivity measurement, one of the doped specimens was again irradiated at liquid helium temperature. After the isochronal annealing at stages I and II, where enhancement of recovery due to the doping treatment is observed, the specimens were brought up to room temperature and annealed further at higher temperatures to investigate stage III. Before the onset of the stage III recovery, the resistivity remaining in the as-doped specimen (specimen 1 ) is given by

$$
\Delta \rho_{1}=\Delta \rho_{D}(\mathrm{III})+\Delta \rho_{D}(\mathrm{IV}, \mathrm{V})
$$

where $\Delta \rho_{D}$ (III) is the resistivity to recover in stage III
In order to test the relation, $\Delta \rho_{D}{ }^{\prime}(\mathrm{III})+\Delta \rho_{L . I .}{ }^{\prime}$ (III) $-\Delta \rho_{D}$ (III) was calculated and compared with $\Delta \rho_{L . I}$ (III). Fig. 5 shows the results of comparison, where the doping time was chosen to be $27.5 \mathrm{hr}$ and $54 \mathrm{hr}$, and the low temperature irradiation time was $18.7 \mathrm{hr}$. Note that the specimens 1 and 2 are simultaneously irradiated at room temperature and also specimens 2 and 3 are also simultaneously irradiated at liquid helium temperature. As seen from Fig. 5, the difference of the differential recovery curve, $\mathrm{d} / \mathrm{d} T\left(\Delta \rho_{D}{ }^{\prime}(\mathrm{III})+\Delta \rho_{L .1 .}^{\prime}(\mathrm{III})\right)-\mathrm{d} / \mathrm{d} T\left(\Delta \rho_{D}(\mathrm{III})\right)$, shifts to lower temperatures with increasing doping dose. However, the difference of the recovery amount, $\Delta \rho_{D}{ }^{\prime}$ (III) $+\Delta \rho_{L . I .}{ }^{\prime}(\mathrm{III})-\Delta \rho_{D}$ (III), is almost comparable with $\Delta \rho_{L . Y}$. (III) (se Table 3). This result seems to indicate that the stage III defect is not lost during the process of the enhancement in stages I and II.

The results of the doping experiments are summarized as follows :

(1) The amounts of recovery in stages I and II are 


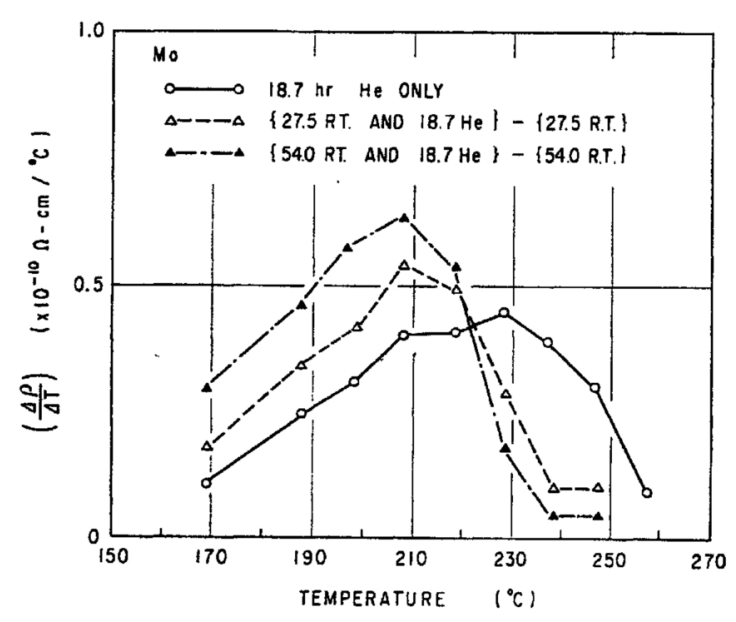

Fig. 5 The comparison of the (A-B) curves in Fig. 4 with the stage III recovery in the only low temperature irradiated specimens. Note that the amount of recovery $(A-B)$ is almost comparable with that of the only low-temperature irradiated specimen (also see Text and Table 3). investigation of damage rate in electron irradiated Mo at $77^{\circ} \mathrm{K}^{(9)}$. The purity dependence of the $60^{\circ} \mathrm{K}$ stage observed in the present research, as well as these results, indicates this stage to correspond to the free interstitial migration.

As a consequence of the assignment of the free interstitial migration to the $60^{\circ} \mathrm{K}$ stage, the $42^{\circ} \mathrm{K}$ peak, the major peak in Mo stage $\mathrm{I}$, is considered to correspond to the correlated annihilation of interstitials with their own vacancies as inferred from the recovery model of stage I of $\mathrm{Cu}^{(13)}$. The atomic number vs. major peak temperature diagram by Coltman et al. ${ }^{(4)}$ also supports this assignment. The $28^{\circ} \mathrm{K}$ peak is considered to be a close pair recovery, which is also inferred from the stage I model of $\mathrm{Cu}$.

As seen from Fig. 1, most of substages in stage II are not reproducible in specimens with different purity. This indicates that impurities are involved in the recovery processes in stage II. In the recovery model of $\mathrm{Cu}$, the stage II is interpreted as the annihilation of interstitials

Table 3 Summary of the stage III recovery in the only doped and the doped and low temperature irradiated specimen.

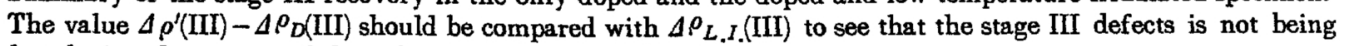
lost during the process of the enhancement in stages I and II

\begin{tabular}{|c|c|c|c|c|c|c|}
\hline & $\begin{array}{l}\text { Dope } \\
\text { (hr) }\end{array}$ & $\underset{(\mathbf{h r})}{L . I .}$ & $\Delta \rho_{D}(\mathrm{III})$ & $\Delta \rho^{\prime * *(\mathrm{III})}$ & $\Delta \rho^{\prime}(\mathrm{III})-\Delta \rho_{D}(\mathrm{III})$ & $\Delta \rho_{L, I .}(\mathrm{III})$ \\
\hline Sp. 3 & 0 & 18.7 & - & - & - & $2.76 \pm 0.1$ \\
\hline $\begin{array}{l}\text { Sp. } 1 \\
\text { Sp. } 2\end{array}$ & $\begin{array}{l}27.5 \\
27.5\end{array}$ & $\begin{array}{c}0 \\
18.7\end{array}$ & $\begin{array}{c}2.76^{*} \pm 0.1 \\
-\end{array}$ & $5.46^{* * *} \pm 0.1$ & $2.70 \pm 0.2$ & - \\
\hline $\begin{array}{l}\text { Sp. } 1 \\
\text { Sp. } 2\end{array}$ & $\begin{array}{l}54.0 \\
54.0\end{array}$ & $\begin{array}{c}0 \\
18.7\end{array}$ & $\begin{array}{c}4.06 \pm 0.1 \\
-\end{array}$ & $7.04^{* * *} \pm 0.1$ & $2.98 \pm 0.2$ & - \\
\hline
\end{tabular}

* In unit of $\left(10^{-9} \Omega-\mathrm{cm}\right) \quad * * \Delta \rho^{\prime}(\mathrm{III})=\Delta \rho_{D^{\prime}}^{\prime}(\mathrm{III})+\Delta \rho_{L . I .}^{\prime \prime}(\mathrm{III})$

increased by radiation doping at room temperature.

(2) The increase tends to saturate with increasing doping dose.

(3) The effect of the doping treatment is almost lost if the doped specimen is annealed at $400^{\circ} \mathrm{C}$ prior to the low temperature irradiation.

(4) The amount of the stage III recovery in the doped and low temperature irradiated specimen is close to the sum of the recovery in the low temperature irradiated spccimen and that in the only doped specimen. No decrease or enhancement of the stage could be detected in the present experiment.

\section{Discussion}

\section{Recovery stage below room temperature}

The retardation of the recovery amount with increasing impurity content in the $60^{\circ} \mathrm{K}$ stage (see Fig. 1) is analogous with the impurity dependence of stage $I_{E}$ in $\mathrm{Cu}^{(13)}$, which is interpreted as a long range migration of interstitials. The internal friction measurement of electron irradiated Mo by Lomer et al. (7) indicates the pinning of dislocation by point defects takes place between $50^{\circ} \mathrm{K}$ and $70^{\circ} \mathrm{K}$, which is usually observed when defects perform a long range migration. The long range migration of interstitials is also suggested by the

(13) J.W.Corbett, R.B.Smith and R. M.Walker : Phys. Rev., 114 (1959), 1460.
**** Average of two measurements

detrapped from impurities. This process is also the most probable one in the case of Mo stage II.

\section{Effect of radiation doping}

In the case of fast neutron damage, defects are concentrated in a rather limited region of the crystal. Hence, the local concentration of interstitials and vacancies are considered to be high. This kind of defects distribution is actually demonstrated by a computer simulation of the fast neutron damage by Beeler et al. (14) The defects distribution in a Mo specimen is considered to be similar to this distribution after low temperature irradiation. When temperature is raised and interstitials become mobile, part of interstitials recombines with their own (correlated recovery) and other (uncorrelated recovery) vacancies. However, because of the high local concentration of defects, part of interstitials will collide with other interstitials and form interstitial clusters. The resistivity recovered $(\Delta \rho)$ in these processes are given by

$$
\begin{array}{ll}
I+V=0 & \Delta \rho=\Delta \rho_{I}+\Delta \rho_{V} \\
I+I=\text { cluster } & \Delta \rho=0,
\end{array}
$$

where $\Delta \rho_{I}$ and $\Delta \rho_{V}$ are the resistivity due to an interstitial and a vacancy, respectively. It is assumed that the resistivity of an interstitial is not altered upon the formation of a cluster. As an evidence of the process

(14) J. E. Beeler and D. G. Besco : J. Appl. Phys., 34 (1963), 2873. 
(5b), we may count the fact that the resistivity remaining in the only low temperature irradiated specimen after the completion of stages I and II is much higher than the resistivity increase due to room temperature irradiation of the same dose (see Fig. 6). In the latter case, the instantaneous concentration of interstitials is low, so that the process $(5 \mathrm{~b})$ does not take place appreciably.

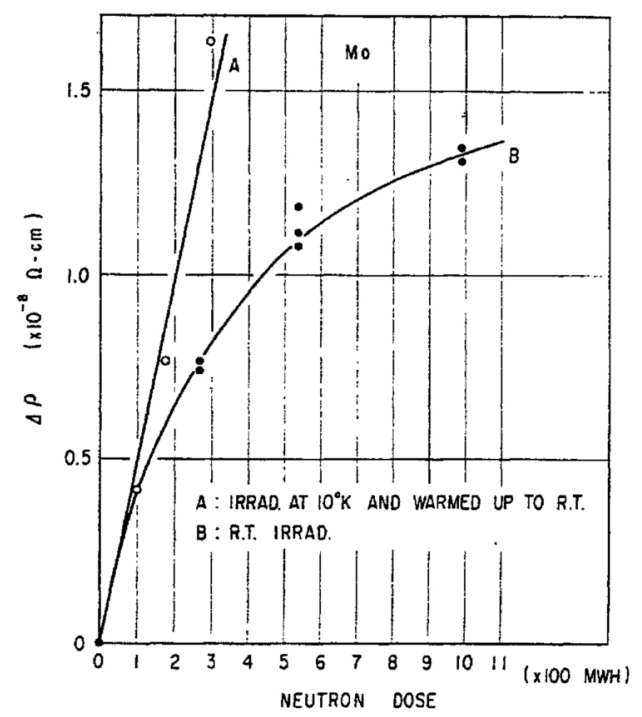

Fig. 6 The comparison of the resistivity in the low temperature irradiated specimen left after the annealing up to $308^{\circ} \mathrm{K}$ with the resistivity increase in the room temperature irradiated specimen. The difference is considered to be due to the higher concentration of interstitial clusters in the former specimen (see Text).

If additional defects $\left(S_{D}\right)$ are introduced by the doping treatment prior to low temperature irradiation, they can act as sinks for interstitials and some fraction of the interstitials, which would form clusters during stages I and II recovery in a only low temperature irradiated specimen, annihilate to these sinks in the doped specimen. The resistivity change in this case is given as

$$
\begin{array}{lr}
I+V=0 & \Delta \rho=\Delta \rho_{I}+\Delta \rho_{V} \\
I+S_{D}=0 & \Delta \rho_{E}=\Delta \rho_{I}+\Delta \rho_{S} \\
I+I=\text { cluster } & \Delta \rho=0,
\end{array}
$$

where $S_{D}$ designates the additional sinks produced by the doping irradiation and $\Delta \rho_{S}$ is the resistivity change due to the annihilation of the sink. The additional resistivity recovery $\left(\Delta \rho_{E}\right)$ is observed as the enhancement. The most probable defects induced by the doping, which can act as sinks for interstitials, are vacancies. The other conceivable defects may be interstitial clusters which grow around impurity atoms during doping irradiation. The large clusters may be considered as dislocation loops and hence can absorb interstitials. The absorption of interstitials to the cluster gives rise to a resistivity decrease. However, if one compares the concentration of the interstitial clusters with that of vacancies, one cannot consider the interstitial clusters as the dominant sinks to give rise to the enhancement. Suppose that the average cluster consists of $n$ interstitial atoms. Then, the concentration of the clusters is $1 / n$ of that of the corresponding vacancies, because vacancies and interstitials are produced in an equal number during the doping irradiation. Hence, in the process of the enhancement, the probability of an interstitial to collide with the doped vacancies should be much higher than that with the clusters.

In the following, we will discuss the experimental results $(1) \sim(4)$ in terms of vacancy sink model and neglects the effect due to the clusters.

If the vacancy sink model of the enhancement is correct, the probability of an interstitial atom to meet the additional vacancies should be proportional to the concentration of the additional vacancies introduced by the doping. The resistivity increase during doping is $7.5 \times$ $10^{-9} \mathrm{ohm}-\mathrm{cm}$ for the $22 \mathrm{hr}$ doping and $12 \times 10^{-9} \mathrm{ohm}-\mathrm{cm}$ for the $64 \mathrm{hr}$ doping. On the other hand, the enhancement is $12 \%$ or $1.4 \times 10^{-9} \mathrm{ohm}-\mathrm{cm}$ for the $22 \mathrm{hr}$ doping and $19 \%$ or $2.2 \times 10^{-9} \mathrm{ohm}-\mathrm{cm}$ for the $64 \mathrm{hr}$ doping at $308^{\circ} \mathrm{K}$ (end of stage II). The ratio of the enhanced resistivity to the doping induced resistivity is about 0.18 regardless the time of the doping irradiation (see Table 2). This result seems to support the idea that the enhancement is proportional to the vacancy concentration. The production rate of resistivity at room temperature tends to saturate with increasing dose due to radiation annealing. Hence, the observation (2) is due to the saturation tendency of vacancy concentration with dose during doping irradiation. The observation (3) shows that vacancies annihilate during the annealing at $400^{\circ} \mathrm{C}$. The annihilation can take place by either (i) the migration of vacancies in stage III or (ii) the migration of defects other than vacancies and their recombination with vacancies. The observation (4) is important to distinguish these two cases. The recovery amount in the stage corresponding to the vacancy annealing should be reduced by the increased amount in stages I and II in the doped and low temperature irradiated specimen. The amount of enhancement is $2.2 \times 10^{-9} \mathrm{ohm}-\mathrm{cm}$ for the $64 \mathrm{hr}$ doping and hence $5 \times 10^{-4}$ at $\%$ of extra Frenkel pairs annihilated $\left(4.5 \mu \mathrm{ohm}-\mathrm{cm} / \mathrm{at} \%{ }^{(6)}\right.$ is assumed for the Frenkel pair resistivity.) Hence, the resistivity of the vacancies lost during the low temperature recovery is $10^{-9} \mathrm{ohm}-\mathrm{cm}$ assuming $2 \mu \mathrm{ohm}-\mathrm{cm} / \mathrm{at} \%$ for vacancy resistivity. The resistivity decrease of $10^{-9} \mathrm{ohm}-\mathrm{cm}$ should be detectable when the resistivity recovery in the doped and irradiated specimen is compared with the sum of those in the only doped and the only low temperature irradiated specimens. The present result of the stage III measurement on the doped specimen does not show the decrease. Hence, the vacancy stage should be higher than the so-called stage III or the case (i), the migration of vacancies in stage III, is not valid.

However, the present model of the enhancement should be taken with some reserve, since no positive evidence of the model, namely, the retardation of the vacancy stage, was not actually investigated. 'Further measurements of a higher stage on the doped specimen are definitely required to put forward the present model.

\section{Acknowledgment}

Invaluable helps given by the members of LHTL group and JRR-3 are gratefully acknowledged. 